\title{
Cluster Against Climate
}

\author{
Oleg Khalidullin* \\ Academician of the Russian Federation LAN, Kazakh National University, Russia
}

*Corresponding author: Oleg Khalidullin, Academician of the Russian Federation LAN, Kazakh National University, Russia

\section{Introduction}

Life on Earth depends on the circuit of water, carbon and everything that rises into the sky. In the atmosphere, their mixing, concentration, various chemical-physical processes, transformations take place, and with precipitation everything returns to the earth. On the soil, substances become the building material of bodies and plants, which, as they grow and multiply, produce waste, eat up, and waste again rise into the sky.

Humanity, in its development and the pursuit of the comfort of its existence, destroys the circuits. Vapors without changing the properties of vapors are clearly visible on the water - it came

with precipitation and immediately went back to the atmosphere. In nature, such fumes come from the surfaces of water bodies, from stones, and other hard surfaces. But with the development of the industry, there are a lot of hard and impermeable surfaces, their volumes grow daily with the growth of technology and productivity. Alienated from nature territories - already more than $70 \%$ of the earth's land. This is deep plowing agriculture, reservoirs, deforestation, asphalt and concrete pavement, garbage and ore landfills. Vapors new to nature from destroyed surfaces can be called artificial. More details can be found in: https://www. actascientific.com/ASMI/pdf/ASMI-SI-01-0009.pdf

One of the types of impermeable surfaces is garbage and ore landfills. Household garbage, in which a lot of chemical elements are concentrated, becomes the endpoint of many substances - the circuits open. At garbage landfills, rainwater moistens the upper layers of paper, plastic, metal, glass, does not find its consumers and returns to the atmosphere without fulfilling its natural functions. The main impact on nature - reducing the water cycle - is the destruction of underground infrastructure, which is located under layers of garbage. Each hectare of natural soil contains up to 20 tons of underground living creatures. All this lives, consumes water, oxygen, carbon dioxide and other gases, converts minerals and organics, releases moisture vapor, and everything else in processed form, is an important link in a single cycle of substances. It was determined that the total garbage area of the whole world occupies the same area as the entire territory of Mexico, which is growing with the development of technology (Figure 1).

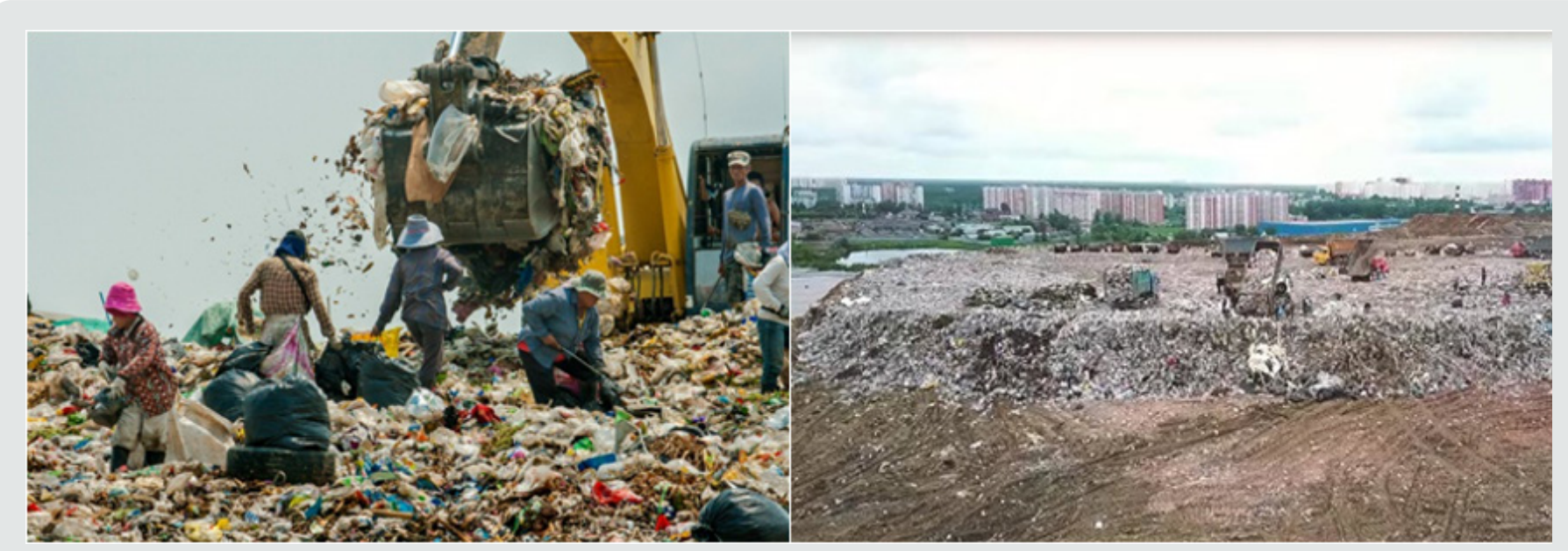

Figure 1: 
All cities in the world solve the problems of recycling and recycling. The greatest success in this was achieved by the Scandinavian countries and Japan. They were able to create zero emissions, eliminated all landfills. All garbage is sorted and recycled; its own circuit of things has formed. These include metals, glass, paper, plastic, organics. All this goes to recycling and returns to reusable items. The destructive effects of these countries on natural processes are significantly reduced.

Examining garbage heaps, we find in their environment most of all plastic containers and bags that are on shelves and shop windows with liquid and bulk products, detergents, chemicals from many industries. The technology for manufacturing plastic dishes has achieved high results in terms of productivity, production volumes, and cost. Is it possible to combine or combine the action and reaction of these two categories: production and utilization. One of the main advantages of plastic products is durability - hundreds of years. But this advantage turns into a disadvantage after using the contents of the container. A variety of processes and studies are underway to reduce plastic because of this durability. Strategically protecting the environment requires reducing or eliminating the production of any kind of plastic, processing it after use, and using it in the production of other items. A variety of methods are actually being introduced to reduce the use of plastic bags and separate garbage collection.

We see a significant scatter in volumes, destinations, and packaging forms. The multitude of parameters of only utensils for filling and selling liquid products suggests the unification and standardization of all containers. Combining the efforts of designers of all types of utensils in a single standardization could reduce garbage many times and eliminate landfills. If plastic dishes do not decompose for hundreds of years, then can this factor be used for construction?

The simplest conclusion suggests itself - to make dishes in the form of a hollow brick. There are such cans with handles and corks recessed in the depths of one of the sides. In the construction of walls, these containers after use can be filled with sand, sawdust, crumpled or crushed plastic bags, crushed non-decaying waste of all other types of garbage, and lay the walls out of them. To do this, it is enough to standardize all types of dishes for a single series of sizes, choose the main size of one side of a rectangular shape, for example length, and make the others multiple in width and height. It is not necessary to do this only for plastic - this one Incip can also be used for glassware. Walls are loadbearing, but frame construction with filling annular space with lightly loaded or nonbearing walls is also known.

It is widely known that craftsmen and enthusiasts build houses from ordinary bottles. https://zen.yandex.ru/media/aleksandrov/ v-rossii-uzakonen-jiloi-dom-iz-butylok-chto-esce-mojno-sooruditiz-brosovogo-stroimateriala-5d837f573f548700ad0b38e0. A new form of utensils would allow such an army of builders to lead to the construction of their houses like these so that the replenishment of landfills would stop immediately (Figure 2). In addition, the useful area for food storage, warehousing, transportation would increase. But most importantly, the growth of landfills would cease. And coupled with the reclamation of existing ones, a significant contribution to reducing artificial and increasing organic fumes would appear - the main factor in stopping climate change.

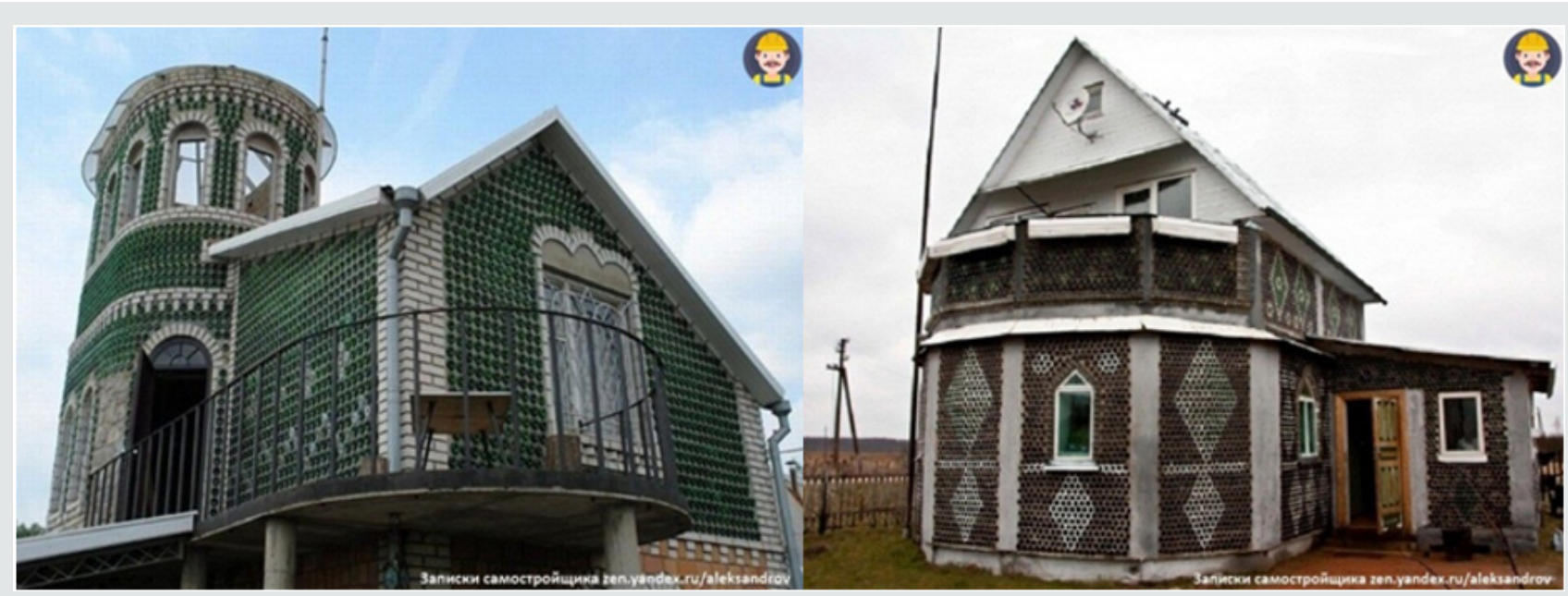

Figure 2: 
(c) (P)

This work is licensed under Creative

Commons Attribution 4.0 License

To Submit Your Article Click Here: Submit Article

DOI: $10.32474 /$ TCEIA.2019.03.000172

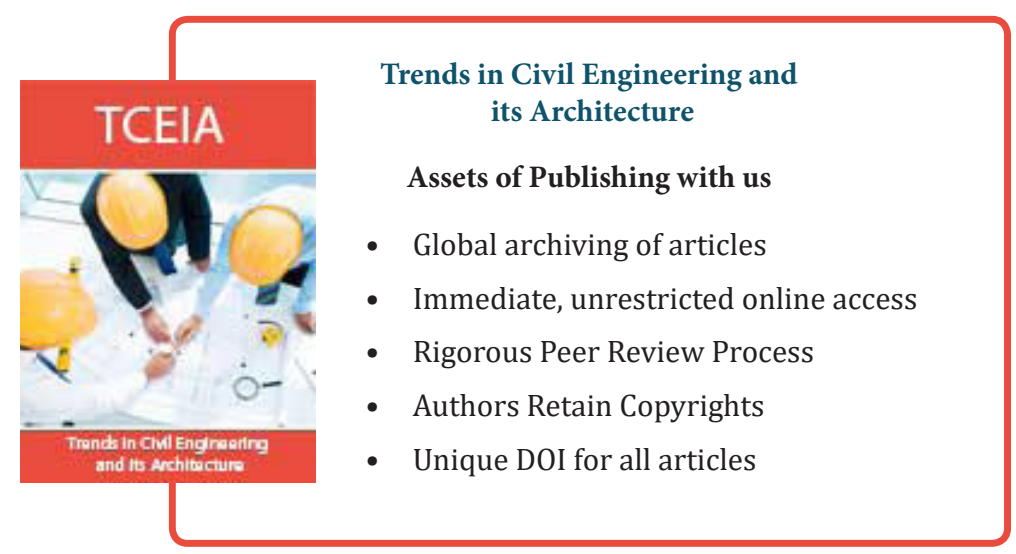

